\title{
Effects of continuous positive airway pressure on lung mechanics of babies after operation for congenital heart disease
}

\author{
J. J. COGSWELL, ^ D. J. HATCH, A. A. KERR, and B. TAYLOR \\ From the Respiratory Unit and Anaesthetic Department, The Hospital for Sick Children, London
}

Cogswell, J. J., Hatch, D. J., Kerr, A. A., and Taylor, B. (1975). Archives of Disease in Childhood, 50, 799. Effects of continuous positive airway pressure on lung mechanics of babies after operation for congenital heart disease. The effect of continuous positive airway pressure (CPAP) on lung mechanics was investigated in 12 babies after operation for severe congenital heart disease. At the time of study all babies were receiving or being weaned from ventilatory support and had abnormally low lung volume or compliance. During CPAP there was a fall in the pulmonary resistance which, with a slight decrease in minute ventilation, resulted in a significant decrease in the work of breathing. It is suggested that lowering the oxygen cost of breathing may contribute to the improvement in arterial oxygenation seen when CPAP is used.

Continuous positive airway pressure (CPAP) is being increasingly used in the management of babies with a variety of respiratory and cardiac disorders (Gregory et al., 1971; Stewart et al., 1973). The technique is being used as an alternative to intermittent positive pressure ventilation in the support of babies after heart surgery (Stewart et al., 1973) and it has been shown that the greatest improvement in arterial oxygenation occurs in those babies in whom lung compliance is low (Hatch et al., 1973).

There are few reports on the changes in lung mechanics during the application of CPA.P to babies in respiratory failure. Gregory and others reported no consistent change in dynamic compliance during the application of CPAP to babies with the idiopathic respiratory distress syndrome (RDS) (Gregory et al., 1971), but Bancalari and others reported a fall in dynamic compliance during continuous negative pressure (Bancalari, Garcia, and Jesse, 1973). There have been no reports of measurements of resistance, or the work of breathing during CPAP or continuous negative pressure.

This paper describes changes in lung mechanics

Received 11 February 1975.

$\star$ Present address: Department of Paediatrics, Guy's Hospital, London. occurring during the application of CPAP to a group of babies with serious pulmonary dysfunction after palliative or corrective cardiac surgery.

\section{Materials and methods}

Fourteen studies of lung mechanics were made in 12 babies with congenital heart disease. Clinical details of the babies are given in Table I. Four babies were studied within 4 days of operation, and were being satisfactorily weaned from their postoperative ventilatory support. The remaining 8 babies had required postoperative ventilation for longer than normal because of their cardiorespiratory state, and were still receiving ventilatory support for some part of each day. Operation was palliative in 3 babies and corrective in 9. The study was approved by the ethical committee of the hospital.

Before each study the babies were sedated with chloral hydrate $50-100 \mathrm{mg} / \mathrm{kg}$. Mechanical ventilation was temporarily discontinued to allow fusurements of lung mechanics to be made during spontaneous breathing, and no measurements were made until a steady state had been obtained. The continuous positive airway pressure was applied by a system previously described (Hatch et al., 1973). Observations of the lung mechanics were made initially when the airway pressure was atmospheric, then during varying levels of CPAP, and finally at atmospheric pressure again.

Measurements of lung mechanics were determined by established techniques (Cook et al., 1957; Karlberg 
TABLE I

Clinical data on 12 babies

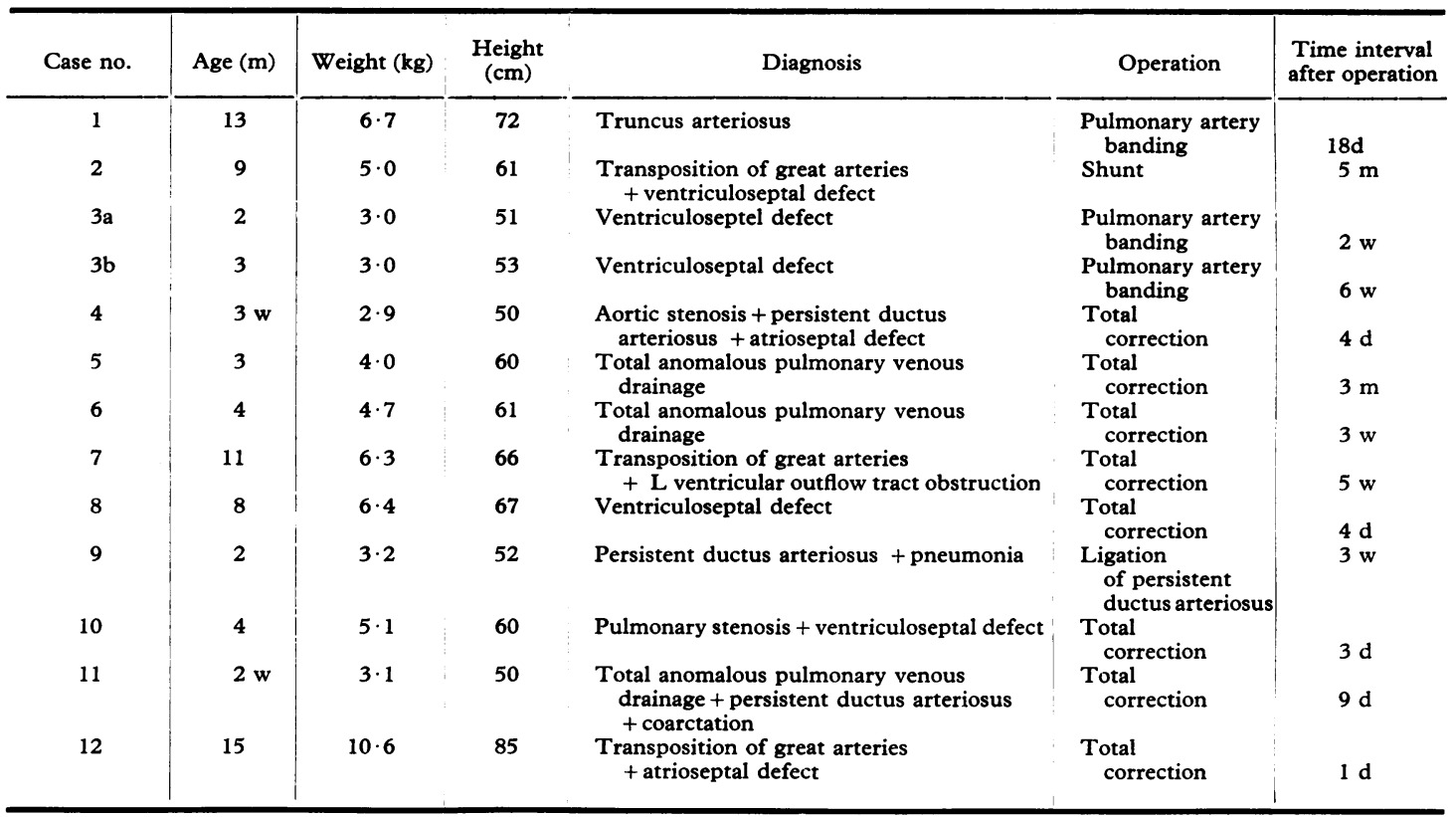

et al., 1960; Swyer, Reiman, and Wright, 1960). Respiratory rate and airflow in the airway were recorded by a pneumotachograph ${ }^{\star}$ connected to a differential pressure transducert.

Tidal volume was obtained from the integrated flow signal. The flow signal was calibrated with an accurate flow meter, and the volume was calibrated by known volumes delivered from a calibrated glass syringe. Oesophageal pressure changes were measured with a thin walled air-filled latex balloon positioned in the lower third of the oesophagus. Each balloon was $5 \mathrm{~cm}$ long, had an external circumference of $1.5 \mathrm{~cm}$, and contained $0.2 \mathrm{ml}$ of air. Accurate placement of the oesophageal balloon was checked by a method described by Turner, Mead, and Wohl (1968). After amplification all signals were recorded on a UV recorder. $\ddagger$ The air-filled balloon was attached to a fine polyethylene catheter introduced through the nose of the baby and connected to a strain gauge transducer.§ The strain gauge was calibrated from 0 to $30 \mathrm{cmH}_{2} \mathrm{O}$ with a water manometer before each study.

Minute ventilation was calculated from mean tidal volume $\left(V_{T}\right)$ and respiratory frequency (f) recorded over 30 seconds of regular breathing. Dynamic compliance $\left(\mathrm{C}_{\mathrm{dyn}}\right)$ was obtained by dividing the tidal

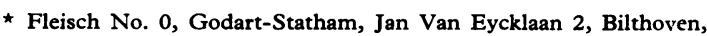
Holland.

† Elema EM32, Elema Schonander AB, S-171, 95, Solna, Sweden.

¥ SE 3006 S.E. Laboratories (Engineering) Ltd., Feltham, Middx., England.

§ SE 4-82 S.E. Laboratories (Engineering) Ltd., Feltham, Middx., England. volume by oesophageal pressure change between points of zero flow. Total pulmonary resistance $\left(\mathbf{R}_{\mathrm{P}}\right)$ was obtained by dividing the oesophageal pressure change by the change in flow measured between midvolume points. The results of $C_{d y n}$ and $R p$ in each individual are the mean of at least 5 measurements made on successive breaths. Total respiratory work was derived from the simplified formula proposed by Cook et al. (1957). Work $(\mathrm{g} \mathrm{cm} / \mathrm{min})=0.6 \times P_{\max } \times$ minute volume, where $P_{\max }$ equals the total oesophageal pressure swing in $\mathrm{cm} \mathrm{H}_{2} \mathrm{O}$ during the respiratory cycle.

The thoracic gas volume (TGV) of each baby was determined before each study of the lung mechanics. A specially designed infant plethysmograph was used for these measurements after the technique described by DuBois et al. (1956). Specific compliance $\left(\mathrm{C}_{\mathrm{sp}}\right)$ was calculated using the formula:

$$
\mathrm{C}_{\mathrm{sp}}=\frac{\mathrm{C}_{\mathrm{dyn}}}{\mathrm{TGV}} \mathrm{ml} / \mathrm{cmH}_{2} \mathrm{O} \text { per ml. }
$$

\section{Results}

Results of the thoracic gas volume (TGV), dynamic compliance, and specific compliance are shown in Table II. In 9 out of 12 studies in which data are complete, specific compliance was reduced (at or below the mean less 2 SD for normal babies) (Phelan and Williams, 1969); the lowest values being found in those babies who had had 
TABLE II

Lung volume and compliance measurements before CPAP

\begin{tabular}{|c|c|c|c|c|}
\hline Case no. & TGV (ml) & TGV (ml) predicted $\star$ & $\begin{array}{c}\text { Dynamic compliance } \\
\left(\mathrm{ml} / \mathrm{cmH}_{2} \mathrm{O}\right)\end{array}$ & $\begin{array}{l}\text { Specific compliance } \\
\left(\mathrm{ml} / \mathrm{cmH}_{2} \mathbf{0}\right)\end{array}$ \\
\hline $\begin{array}{l}1 \\
2 \\
3 \mathrm{a} \\
3 \mathrm{~b} \\
4 \\
5 \\
6 \\
7 \\
8 \\
9 \\
10 \\
11 \\
12\end{array}$ & $\begin{array}{r}267 \\
165 \\
105 \\
113 \\
94 \\
96 \\
116 \\
81 \\
161 \\
38 \\
75 \\
52 \\
-\end{array}$ & $\begin{array}{r}287 \\
174 \\
102 \\
114 \\
96 \\
166 \\
174 \\
221 \\
201 \\
108 \\
166 \\
96 \\
472\end{array}$ & $\begin{array}{r}4 \cdot 1 \\
3 \cdot 2 \\
3 \cdot 4 \\
3 \cdot 5 \\
2 \cdot 6 \\
3 \cdot 4 \\
4 \cdot 3 \\
3 \cdot 0 \\
6 \cdot 0 \\
1 \cdot 7 \\
5 \cdot 4 \\
4 \cdot 1 \\
10 \cdot 9\end{array}$ & $\begin{array}{c}0.015 \\
0.019 \\
0.032 \\
0.031 \\
0.030 \\
0.035 \\
0.037 \\
0.037 \\
0.037 \\
0.045 \\
0.072 \\
0.079 \\
-\end{array}$ \\
\hline
\end{tabular}

* Thoracic gas volume $=0.768 \pm 0.089 \times 10^{-3} \mathrm{ml}$ (height in $\left.\mathrm{cm}\right)^{3}$.

+ Normal specific compliance $=0.056 \pm 0.01$ (means and SD from Phelan and Williams, 1969).

palliative as opposed to corrective surgery. TGV was low (less than two-thirds predicted based on body length) in 6 of the 12 studies, and either or both measurements was abnormally low in all babies.

Values for respiratory rate, tidal volume, maximal oesophageal pressure change, and work of breathing are shown in Table III. Results are recorded at atmospheric pressure $\left(\mathrm{CPAP}=0 \mathrm{cmH}_{2} 0\right)$, at varying levels of continuous positive airway pressure (CPAP $=5-10 \quad \mathrm{cmH}_{2} \mathrm{O}$ and $\left.10-15 \quad \mathrm{cmH}_{2} 0\right)$, and finally at atmospheric pressure $\left(\mathrm{CPAP}=0 \mathrm{cmH}_{2} \mathrm{O}\right)$ at the end of the study.

The mean changes from the initial levels of the dynamic measurements during CPAP are shown in Table IV. Respiratory rate fell in 11 of the 14 studies, but the overall change was not significant. Although there was no consistent change in tidal volume there was a reduction in minute ventilation at the higher level of CPAP.

There was a fall in maximal oesophageal pressure swing and pulmonary resistance during CPAP. These changes, together with the fall in minute ventilation, resulted in a significant drop in the work of breathing. Mean dynamic compliance remained unaltered.

Stopping CPAP was often poorly tolerated by the baby, causing considerable restlessness. In these cases the baby was returned to the ventilator and the final measurements at atmospheric pressure were not obtained. There was, however, a tendency for the pulmonary resistance and work of breathing to rise again in the 6 babies in whom the final value was obtained. The 'overshoot' in the work of breathing seen in Cases 1,3 , and 5 was presumed to be due to hyperventilation.

\section{Discussion}

We have described the changes in lung mechanics during CPAP in a group of babies with abnormal lung function after surgery for congenital heart disease. All had either low pulmonary compliance or low TGV or both before CPAP was applied. In 11 of the 14 studies there was a decrease in the work of breathing during CPAP. In 10 of these there was a decrease in the maximal oesophageal pressure swing during the breathing cycle.

Three components are important in assessment of the work of breathing: the volume of air shifted per unit time (the minute ventilation), the lung compliance, and the pulmonary resistance. The latter two are reflected in the oesophageal pressure swings. Of these three factors, pulmonary resistance showed a significant fall during CPAP in all but 2 infants. This was the main factor contributing to the overall decrease in work. We think this reflects an increase in functional residual capacity. Using the rubber respiratory jacket (Milner, 1970) we have shown such an increase in the end tidal point during CPAP (Hatch, 1974) (Fig.). It was impossible to measure the TGV directly with the whole body plethysmograph during CPAP.

Numerous studies have shown that resistance is dependent on lung volume, decreasing as volume increases (DuBois, 1964). It can be calculated that the mean drop in resistance of $33 \%$ seen in these children could result from a $30 \%$ rise in TGV. From the measured dynamic compliance the expected rise in TGV when a pressure of $10 \mathrm{~cm} \mathrm{H}_{2} \mathrm{O}$ is applied to the lungs would be of that order in most infants. It follows on theoretical 
TABLE III

Individual values for lung mechanics in 12 infants studied

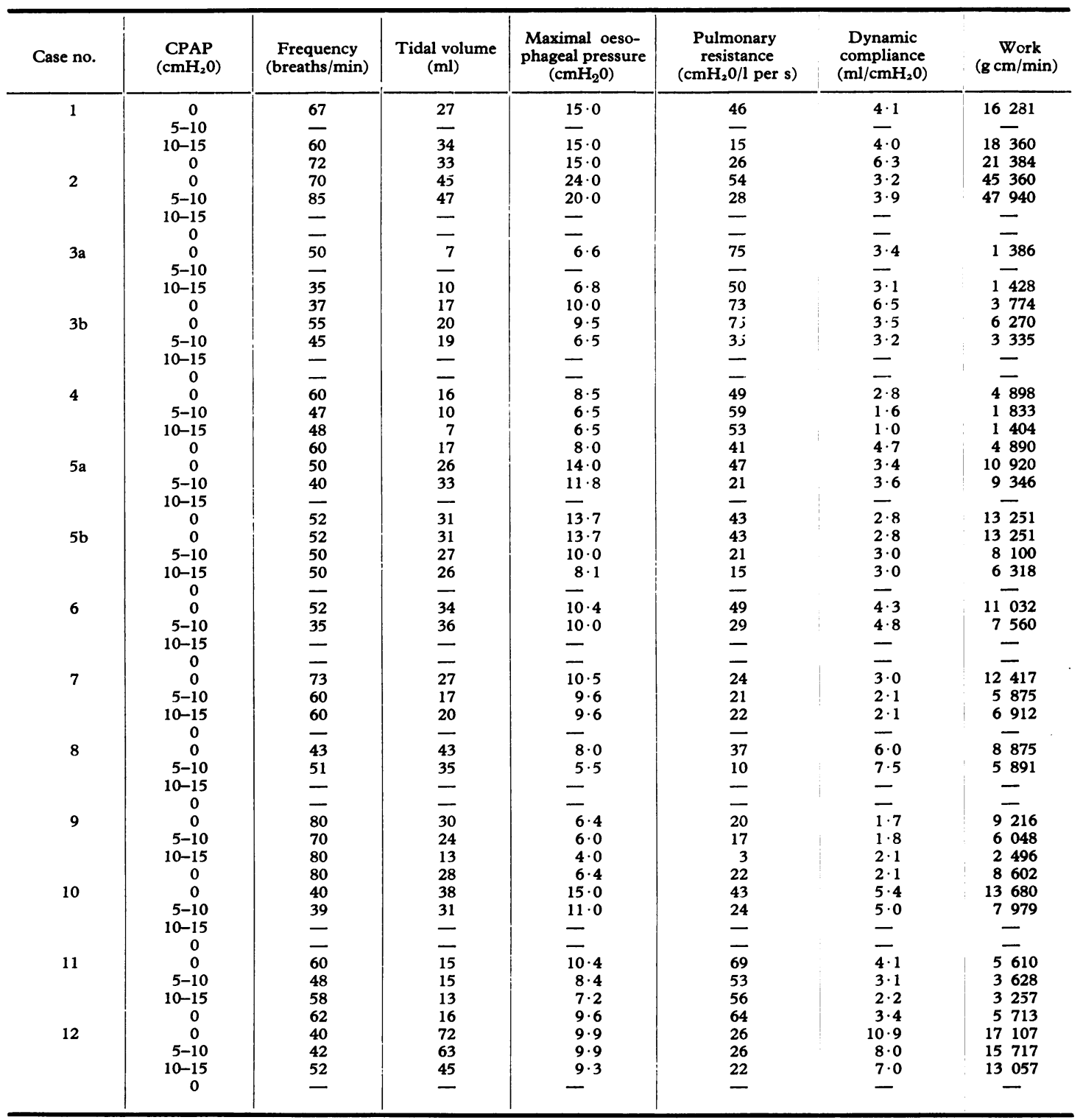

grounds that the fall in resistance is most easily explained by a rise in lung volume.

We have also shown a decrease in the minute ventilation, which became significant at higher applied airway pressure. Breathing frequency and tidal volume both tended to fall but these changes were not significant. Breathing frequency fell immediately CPAP was applied and rose immediately it was stopped, suggesting a reflex mechanism.

We did not show a consistent change in dynamic compliance with CPAP in this study. Gregory et al. (1971) also found variable changes in compliance in newborn infants with idiopathic respiratory distress syndrome (RDS). In contrast, 


\section{TABLE IV}

Effect of CPAP on lung function. Mean data in 12 infants studied expressed as a change from initial values

\begin{tabular}{|c|c|c|c|}
\hline & \multirow{3}{*}{$\begin{array}{l}\text { Mean initial } \\
\text { value }\end{array}$} & \multicolumn{2}{|c|}{ Change from initial value } \\
\hline & & \multicolumn{2}{|c|}{ Level of CPAP $\left(\mathrm{cmH}_{2} 0\right)$} \\
\hline & & $5-10$ & $10-15$ \\
\hline $\begin{array}{l}\text { Number of studies } \\
\text { Frequency (breaths/min) } \\
\text { Tidal volume }(\mathrm{ml}) \\
\text { Minute ventilation }(\mathrm{ml} / \mathrm{min}) \\
\text { Maximal oesophageal pressure }\left(\mathrm{cmH}_{2} \mathrm{O}\right) \\
\text { Pulmonary resistance }\left(\mathrm{cm} \mathrm{H}_{2} \mathrm{O} / \mathrm{p} \text { per s) }\right. \\
\text { Dynamic compliance }\left(\mathrm{ml} / \mathrm{cmH}_{2} \mathrm{O}\right) \\
\text { Work }(\mathrm{gcm} / \mathrm{min})\end{array}$ & $\begin{array}{l}14 \\
56 \cdot 6 \\
30 \cdot 8 \\
1684 \\
11 \cdot 56 \\
47 \\
4 \cdot 19 \\
12593\end{array}$ & $\begin{array}{l}-5 \cdot 3 \\
-3.33 \\
-3 \cdot 33 \\
-242 \\
\star-2 \cdot 09(<0 \cdot 001) \\
\star-15(<0 \cdot 01) \\
-0 \cdot 29 \\
\star-2949(<0 \cdot 005)\end{array}$ & $\begin{array}{l}\quad 8 \\
-4 \cdot 9 \\
-7 \cdot 13 \\
\star-440(<0 \cdot 05) \\
\star-1 \cdot 81(<0 \cdot 05) \\
\star_{-14 \cdot 5(<0 \cdot 02)} \\
-1 \cdot 04 \\
{ }_{-}-3367(<0 \cdot 025)\end{array}$ \\
\hline
\end{tabular}

* Significant change for paired $t$ test on differences from initial values in brackets.

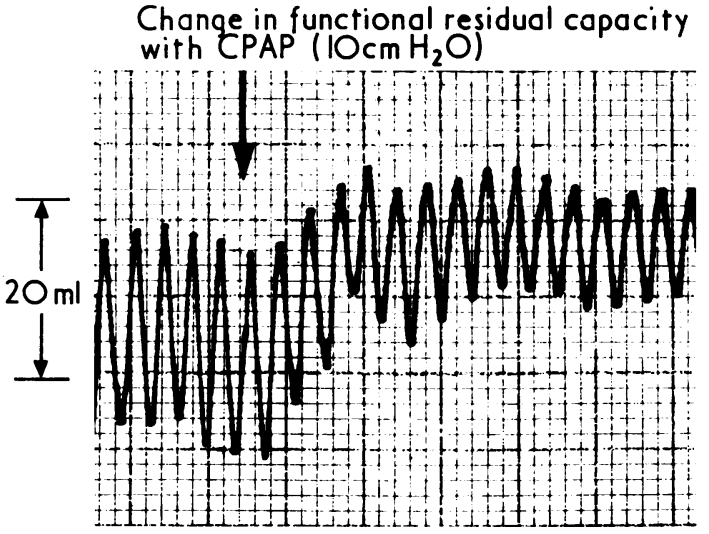

FIG.-Tidal breathing recorded by a rubber respiratory jacket. After CPAP is applied (arrow) there is a rise in the end-tidal position and a decrease in tidal volume.

Bancalari et al. (1973) showed a consistent fall in compliance in this syndrome when they applied a continuous negative pressure to the chest. It is possible that the difference in findings is because the initial dynamic compliance and lung volumes were higher in Bancalari's group of patients. The increase in airway pressure may then have raised the lung volume to the flatter part of the pressurevolume curve (near total lung capacity) with consequent drop in measured compliance. In addition, differences in oesophageal balloon placement and volume may account for some of the discrepancies (Milic-Emili, Mead, and Turner, 1964a; MilicEmili et al., 1964b).

It is well known that the application of CPAP in certain defined situations results in a rise in arterial oxygen tension $\left(\mathrm{PaO}_{2}\right)$. This was first shown in
RDS of the newborn by Gregory et al. (1971) and later after cardiopulmonary bypass in infancy (Stewart et al., 1973; Crew et al., 1974). We have previously shown that the greatest increase in arterial oxygenation is seen in infants with stiff lungs (Hatch et al., 1973). It has been suggested that the main mechanism whereby improved oxygenation occurs with CPAP is an improvement of ventilation: perfusion ratio and a lowering of the physiological dead space. The fact that the arterial $\mathrm{CO}_{2}$ tension does not increase in spite of a reduction in minute ventilation (Gregory et al., 1971) supports this suggestion.

An additional factor in this increase in $\mathrm{PaO}_{2}$ may be the reduced work of breathing. The values for the work of breathing obtained in this study are high compared to the values of Cook et al. (1957) and because of this a greater than normal amount of the total oxygen consumption is used up in this work. Accordingly, a reduction in this work load by $25 \%$, as occurs on average in this study, represents a significant lowering of the total tissue oxygen consumption and should contribute to improved arterial oxygenation by a reduction in venous admixture when there is right to left shunting within the lungs or heart.

We thank Mr. J. Stark, Mr. D. J. Waterston, Dr. R. E. Bonham-Carter, and the staff of the Thoracic Unit for their co-operation.

\section{REFERENCES}

Bancalari, E., Garcia, O. L., and Jesse, M. J. (1973). Effects of continuous negative pressure on lung mechanics in idiopathic respiratory distress syndrome. Pediatrics, 51, 485.

Cook, C. D., Sutherland, J. M., Segal, S., Cherry, R. B., Mead, J., McIlroy, M. B., and Smith, C. A. (1957). Studies of respiratory physiology in the newborn infant. III. Measurements of mechanics of respiration. Fournal of Clinical Investigation, 36, 440 . 
Crew, A. D., Varkonyi, P. I, Gardner, L. G., Robinson, Q. L. A. Wall, E., and Deverall, P. B. (1974). Continuous positive airway pressure breathing in the postoperative management of the cardiac infant. Thorax, 29, 437.

DuBois, A. B. (1964). Resistance to breathing. Handbook of Physiology, Section 3: Respiration, Vol. I, p. 451. Ed. by W. O. Fenn and H. Rahn. American Physiological Society, Washington, D.C.

DuBois, A. B., Botelho, S. Y., Bedell, G. N., Marshall, R., and Comroe, J. H., Jnr. (1956). A rapid plethysomographic method for measuring thoracic gas volume; a comparison with a nitrogen washout method for measuring functional residual capacity in normal subjects. Fournal of Clinical Investigation, $35,322$.

Gregory, G. A., Kitterman, J. A., Phibbs, R. H., Tooley, W. H., and Hamilton, W. K. (1971). Treatment of the idiopathic respiratory distress syndrome with continuous positive airway pressure. New England fournal of Medicine, 284, 1333.

Hatch, D. J. (1974). Respiratory measurement in infancy. Modern Trends in Anaesthesia: Paediatric Anaesthesia. Ed. by T. C. Gray and G. J. Rees. Butterworths, London. (New ed. in press.)

Hatch, D. J., Cogswell, J. J., Taylor, B. W., Battersby, E. F. Glover, W. J., and Kerr, A. A. (1973). Continous positiveairway pressure after open-heart operations in infancy. Lancet, $7,469$.

Karlberg, P., Cherry, R. B., Escardo, F., and Koch, G. (1960). Respiratory studies in newborn infants. I. Apparatus and methods for studies of pulmonary ventilation and the mechanics of breathing. Principles of analysis in mechanics of breathing. Acta Paediatrica, 49, 345.

Milic-Emili, J., Mead, J., and Turner, J. M. (1964a). A topography of esophageal pressure as a function of posture in man. Fournal of Applied Physiology, 19, 212.

Milic-Emili, J., Mead, J., Turner, J., and Glauser, E. M. (1964b) Improved technique for estimating pleural pressure from esophageal balloons. Fournal of Applied Physiology, 19, 207.

Milner, A. D. (1970). The respiratory iacket. Lancet, 2, 80.

Phelan, P. D., and Williams, H. E. (1969). Ventilatory studies in healthy infants. Pediatric Research, 3, 425.

Stewart, S., Edmunds, L. H., Kirklin, J. W., and Allarde, R. R. (1973). Spontaneous breathing with continuous positive airway pressure after open intracardiac operations in infants. fournal of Thoracic and Cardiovascular Surgery, 65, 37.

Swyer, P. R., Reiman, R. C., and Wright, J. J. (1960). Ventilation and ventilatory mechanics in the newborn. Fournal of Pediatrics, 56, 612.

Turner, J. M., Mead, J., and Wohl, M. E. (1968). Elasticity of human lungs in relation to age. Fournal of Applied Physiology, 25, 664 .

Correspondence to Dr. D. J. Hatch, Respiratory Unit, The Hospital for Sick Children, Great Ormond Street, London WC1N 3JH. 